\title{
On the effectiveness of tailored mesoporous MFI zeolites for biomass catalytic fast pyrolysis
}

David P. Gamliel, ${ }^{[a]}$ Hong Je Cho, ${ }^{[b]}$ Wei Fan ${ }^{[b]}$ and Julia A. Valla*[a]

[a]Department of Chemical \& Biomolecular Engineering, University of Connecticut Storrs, 191 Auditorium Road, Unit 3222, Storrs, CT 06269, USA.

${ }^{[b]}$ Department of Chemical Engineering, University of Massachusetts, Amherst, 686 N. Pleasant Street, Amherst, MA 01003-9303, USA.

*Corresponding Author: Tel: +1-860-486-0583. Email: valla@engr.uconn.edu;

\begin{abstract}
Optimum catalyst design plays a pivotal role in maximizing catalytic fast pyrolysis (CFP) bio-oil yield and quality. This work investigates the use of mordenite framework inverted (MFI) zeolites with hierarchical pore structures as potential catalysts to address the aforementioned challenges. Mesoporous MFI catalysts were created using both top-down and bottom-up approaches, were characterized and evaluated as CFP catalysts. CFP with mesoporous catalysts resulted in higher yields to aromatics and lower coke and char yields. The results of this study indicate that there is a maximum amount of mesopore volume required for optimal acid site accessibility leading to increased bio-oil production. After this maximum, intermediate aromatic hydrocarbons continue to polymerize to form bulky poly-cyclic aromatic hydrocarbons (PAHs) and coke.
\end{abstract}

KEYWORDS: • Heterogeneous catalysis • Biomass Conversion • Catalytic Fast Pyrolysis • ZSM-5 • Hierarchical Zeolites 


\section{Introduction}

Thermochemical conversion of biomass has already begun to contribute renewable energy and fuels to the ever-expanding industrial market [1]. One prevalent technique for conversion of biomass to fuels and commodity chemicals is fast pyrolysis; the rapid heating of biomass to elevated temperatures $\left(400-700^{\circ} \mathrm{C}\right)$ under an inert atmosphere [2]. During the pyrolysis process lignin, cellulose and hemi-cellulose, break down to form liquid oxygenates, such as phenols, furans and soluble sugars. Fast pyrolysis in the presence of an upgrading catalyst is known as catalytic fast pyrolysis (CFP). Intermediate pyrolysis oxygenates contact the catalyst acid sites, where they react to form single ring aromatic compounds, naphthalenes, poly-cyclic aromatic hydrocarbons (PAHs) and/or coke. Aromatic product selectivity can be enhanced based on the choice of catalyst. Thus, catalyst design is crucial for improving yields to valuable chemicals.

Significant scientific effort has been devoted to the design of the ideal CFP catalyst. Zeolitic materials have widely been accepted as the most promising CFP catalysts owing to their welldefined shape selective microporous structure and high acidity [3]. Jae et al. [4] studied CFP of glucose with a wide variety of alumino-silicate catalysts. They created a volcano curve correlating average zeolite pore diameter and aromatic yield, and found that the mordenite framework inverted (MFI) zeolite has the ideal pore size and acidity for production of aromatics from biomass pyrolysis. As a result, ZSM- 5 with a Si/Al ratio between 15 and 40 has been the catalyst of choice for many studies in the field of biomass CFP [5-8]. However, low bio-oil yields, with low aromatics content, and formation of coke on catalyst continue to hamper the commercialization of biomass CFP technology.

One possible source of the aforementioned challenges may be the presence of transport limitations in the catalyst pore structure. Bulky oxygenates formed during the initial stages of pyrolysis may not be able to efficiently reach the active sites within the catalyst micropores. For example, many of the oxygenates formed from lignin pyrolysis have dimensions larger than the effective pore opening of ZSM-5 [9]. Application of a mesoporous catalyst can be advantageous, as enlarging the pore structure results in increased accessibility of reactants to catalyst acid sites [10]. There are two broad approaches for the creation of mesoporous zeolites; the so-called top- 
down and bottom-up strategies. Top-down methods involve introduction of mesoporosity by post-synthetic methods, such as: desilication [11-14], dealumination (steaming or acid treatment) $[15,16]$ and desilication in the presence of surfactant $[17,18]$ or a pore directing agent [19-21]. Bottom-up methods rely on introduction of mesoporosity during hydrothermal zeolite synthesis. Common bottom-up methods include exfoliation and pillaring of layered zeolites, hard templating, supramolecular templating and self-assembly of zeolite crystals or nanocrystals [22-26].

Mesoporous MFI type zeolites for biomass CFP have been studied by several research groups. Park et al. [27] prepared mesoporous ZSM-5 zeolites using top-down and bottom-up techniques $[23,28]$, and studied their effectiveness in upgrading sawdust pyrolysis vapors. They observed that upgrading with any of the mesoporous catalysts resulted in higher solid yields, compared to upgrading with a commercial ZSM-5 zeolite. Additionally, they concluded that upgrading with the mesoporous ZSM-5 catalyst synthesized with the bottom-up approach resulted in significantly higher yields to mono-aromatic hydrocarbons (MAHs) and less PAHs than the commercial ZSM-5, due to the synergistic effects of acidity and mesoporosity. Upgrading with the mesoporous ZSM-5 created using the top-down approach resulted in significant amounts of oxygenates, most likely as a result of lower zeolite acidity compared to the parent ZSM-5. Park et al. [29] also compared pyrolysis of miscanthus with a commercial ZSM-5 zeolite and templated mesoporous ZSM-5 zeolite. They found improved yields to aromatics and phenols with the mesoporous zeolite, concluding it was the most adequate for biomass CFP. Puértolas et al. [30] studied upgrading of bio-oil over hierarchical zeolites with different $\mathrm{Si} / \mathrm{Al}$ ratios prepared by desilication. They observed an increase in the solid yield (coke) and a decrease in the liquid yield over their hierarchical zeolites, compared to the parent material. On the other hand, they noted an increase in aromatic products yield of up to 50\% using the mesoporous materials. They attributed these differences to changes in acidity, preferential decarbonylation over hierarchical zeolites and increased pore accessibility.

Foster et al. [31] pyrolyzed maple wood and biomass model compounds in the presence of mesoporous and microporous MFI zeolites. They found that CFP with mesoporous catalysts 
favored the formation of alkyl aromatics, fewer liquids and more solids. Li et al. [10] performed CFP of beech wood with a series of desilicated ZSM-5 catalysts. Contrary to Foster et al., they found that increasing the mesopore volume increased the aromatic yield, particularly to naphthalenes, and decreased the coke yield. They determined that beyond a mesopore volume of $0.127 \mathrm{~cm}^{3} \mathrm{~g}^{-1}$, the aromatics previously gained were lost to coke.

The above review highlights the current debate on the effects of mesoporous MFI catalysts on CFP bio-oil composition and coke yield. The objective of this work is to gain a better understanding of how hierarchical pore structure MFI zeolites affect diffusion and reaction during CFP, and consequently, product yields and bio-oil quality. Top-down and bottom-up techniques were employed to create a wide variety of MFI-type catalysts with ranging mesoporosity. Each catalyst has been characterized to determine the pore structure, acidity and crystallinity. CFP of cellulose and miscanthus has been performed with the MFI zeolites to determine how the intrinsic properties of the various mesoporous catalysts affect CFP of a model and real biomass.

\section{Materials and methods}

\subsection{Preparation of hierarchical MFI zeolite}

\subsubsection{Bottom-up methods}

Preparation of $100 \mathrm{~nm}$ MFI zeolite was carried out using a method reported in literature [32]. Briefly, $6.00 \mathrm{~g}$ of tetraethylorthosilicate (TEOS, Sigma Aldrich) was added to $3.66 \mathrm{~g}$ of $40 \%$ tetrapropylammonium hydroxide solution (TPAOH, Alfa Aesar or SACHEM). The resulting mixture was stirred at $80{ }^{\circ} \mathrm{C}$ for $24 \mathrm{~h}$. Thereafter, the solution containing $2.37 \mathrm{~g}$ of distilled water, $0.23 \mathrm{~g}$ of $\mathrm{Al}\left(\mathrm{NO}_{3}\right)_{3} \bullet 9 \mathrm{H}_{2} \mathrm{O}(98 \%$, Sigma Aldrich) and $0.29 \mathrm{~mL}$ of $10 \mathrm{M} \mathrm{NaOH}$ solution was added to the mixture. The molar composition of the final gel was $1 \mathrm{SiO}_{2}: 0.25 \mathrm{TPAOH}: 0.0167$ $\mathrm{Al}_{2} \mathrm{O}_{3}: 0.05 \mathrm{Na}_{2} \mathrm{O}: 9.45 \mathrm{H}_{2} \mathrm{O}$. The prepared gel was crystallized at $170{ }^{\circ} \mathrm{C}$ for $24 \mathrm{~h}$. The solid

product was collected by centrifugation. The H-form of the $100 \mathrm{~nm}$ MFI zeolite was obtained by calcination at $550{ }^{\circ} \mathrm{C}$ for $12 \mathrm{~h}$ in air. This material is referenced as MFI-100nm. 
Mesoporous MFI zeolite was prepared using a method reported in the literature [22]. Concisely, $0.23 \mathrm{~mL}$ of $10 \mathrm{M} \mathrm{NaOH}$ solution was mixed with $20.80 \mathrm{~g}$ of $1 \mathrm{M}$ TPAOH (Sigma Aldrich). Subsequently, $12.50 \mathrm{~g}$ of Ludox HS-40 (Sigma Aldrich) was added dropwise to the mixture. A transparent solution was formed after stirring the mixture for $1 \mathrm{~h}$. $0.57 \mathrm{~g}$ of aluminum isopropoxide (98\%, Sigma Aldrich) was added and completely dissolved into the solution by stirring for $30 \mathrm{~min}$. The final composition of the mixture was $1 \mathrm{SiO}_{2}: 0.25 \mathrm{TPAOH}: 0.017 \mathrm{Al}_{2} \mathrm{O}_{3}$ : $0.014 \mathrm{Na}_{2} \mathrm{O}: 16.44 \mathrm{H}_{2} \mathrm{O}$. Hydrothermal treatment was carried out in a Teflon-lined autoclave at $135^{\circ} \mathrm{C}$ for 2 days with a rotation speed of $3 \mathrm{rpm}$. The obtained product was thoroughly washed by filtration with distilled water, followed by drying overnight at $100{ }^{\circ} \mathrm{C}$. The collected sample was calcined in a furnace at $550{ }^{\circ} \mathrm{C}$ for $12 \mathrm{~h}$ in air. This material is referred to as MFI-Meso in this study. Ion exchange was performed with $1 \mathrm{M}$ aqueous solution of $\mathrm{NH}_{4} \mathrm{NO}_{3}$ (95\%, J.T. Baker) at $80{ }^{\circ} \mathrm{C}$ for $3 \mathrm{~h}$ and repeated three times. The final product was obtained in the H-form by calcination at $550{ }^{\circ} \mathrm{C}$ for $8 \mathrm{~h}$ in air.

\subsubsection{Top-down methods}

The parent zeolite for all materials created using top-down approaches was a ZSM-5 zeolite with a Si/Al ratio of 40 (Zeolyst International), referenced in this study as MFI-Pa.

Desilication by alkaline treatment was employed for the top-down introduction of mesoporosity. It was accomplished by stirring MFI-Pa in $0.1 \mathrm{M} \mathrm{NaOH}$ (MFI-DS-Mild) or $0.3 \mathrm{M}$ $\mathrm{NaOH}$ (MFI-DS-Strong) solution at $65{ }^{\circ} \mathrm{C}$ for $30 \mathrm{~min}$. Each material was then subjected to an acid wash in $0.01 \mathrm{M} \mathrm{HCl}\left(25^{\circ} \mathrm{C}, 6 \mathrm{~h}\right)$, followed by three ion exchanges with $0.1 \mathrm{M} \mathrm{NH}_{4} \mathrm{NO}_{3}(25$ ${ }^{\circ} \mathrm{C}, 6 \mathrm{~h}$ ), drying overnight between each step. The final material was calcined in air at $550{ }^{\circ} \mathrm{C}$ for $6 \mathrm{~h}$ to convert the material to the H-form.

It has been suggested that the use of surfactant during desilication is a more refined way of introducing mesoporosity without crystal destruction via redeposition of extracted silica around micelles of surfactant on the zeolite surface $[17,18]$. Thus, desilication in the presence of surfactant was performed by stirring $3.0 \mathrm{~g}$ of MFI-Pa in $0.05 \mathrm{M}$ cetyl-trimethylammonium bromide (CTAB, Sigma Aldrich) and 0.1 M NaOH (MFI-SA-Mild) or 0.3 M NaOH (MFI-SA- 
Strong) at $65{ }^{\circ} \mathrm{C}$ for $30 \mathrm{~min}$. The acid wash, ion exchange and calcination are the same as for the desilication procedure. Table 1 outlines the preparation strategy for each of the materials presented in this work.

\subsection{Characterization of hierarchical MFI zeolites}

The physical properties of each material including surface area and pore size distribution were determined using $\mathrm{N}_{2}$ sorption, which was carried out using a Micromeritics ASAP 2020 Physisorption Analyzer. Prior to analysis, each sample was calcined then degassed for $12 \mathrm{~h}$ at $120{ }^{\circ} \mathrm{C}$ under vacuum. Isotherms were recorded at $77 \mathrm{~K}$, and the Brunauer-Emmett-Teller (BET) method was used to estimate surface area. The non-local density functional theory (NL-DFT) method was applied to the adsorption branch of each isotherm to calculate the pore size distribution using a model specifically designed for $\mathrm{N}_{2}$ adsorption on $\mathrm{H}$ - form zeolites [33,34]. Briefly, this method was developed as a hybrid between statistical mechanical calculations and experimentation methods. The model takes into account variation in $\mathrm{N}_{2}$ fluid density as it enters the zeolite micropores and mesopores, and was originally developed with MCM-41 as a reference [35].

Wide angle X-ray diffraction (XRD) patterns were obtained using a Bruker D8 Advance powder diffractometer with a $\mathrm{CuK} \alpha$ radiation source. Data was collected with a range of $2 \theta$ from $5^{\circ}$ to $40^{\circ}$ and a step size of $0.1^{\circ}$. Quantification of the Si/Al ratio was determined via inductively coupled plasma optical emission spectroscopy (ICP-OES) using a Thermo Scientific iCAP 6500.

Diffuse reflectance infrared Fourier transform spectroscopy (DRIFTs) was used to characterize the $-\mathrm{OH}$ stretching region of each zeolite and quantify Brønsted and Lewis acidity by pyridine adsorption. Spectra were recorded with a Thermo Nicolet 6700 FTIR using a Harrick Praying Mantis DRIFT accessory and reaction chamber fitted with ZnSe windows. Pre-calcined samples were treated in-situ for $1 \mathrm{~h}$ at $550{ }^{\circ} \mathrm{C}$, while purging with $\mathrm{N}_{2}$. All spectra were recorded using 64 scans and a $4 \mathrm{~cm}^{-1}$ resolution. Spectra of the $-\mathrm{OH}$ stretching region were recorded at $130{ }^{\circ} \mathrm{C}$ under inert conditions and with a KBr background. Pyridine adsorption was carried out at 130 ${ }^{\circ} \mathrm{C}$ after calcination using the fresh sample as the background. After adsorption, the sample was 
slowly heated to $250{ }^{\circ} \mathrm{C}$ to remove physisorbed pyridine, and then returned to $130{ }^{\circ} \mathrm{C}$ for the final spectrum.

Isopropylamine (IPA) temperature programmed desorption (TPD) was performed on a TA instruments Q500 according to the method developed by Gorte et al. [36,37]. $0.01 \mathrm{~g}$ of catalyst was first pre-treated at $550{ }^{\circ} \mathrm{C}$ for $1 \mathrm{~h}$ under a He flow to remove moisture and other impurities from the catalyst surface. After cooling to $120^{\circ} \mathrm{C}$, IPA was dosed into the system while flowing He. When the sample was saturated with IPA, the gas flow was switched to He. Sample temperature was increased to $700{ }^{\circ} \mathrm{C}$ with a ramping rate of $10{ }^{\circ} \mathrm{C} \mathrm{min}-1$. The total Brønsted acid site concentration was determined by the weight difference between $300{ }^{\circ} \mathrm{C}$ and $400{ }^{\circ} \mathrm{C} .2,4,6$ trimethylpyridine (collidine, CLD) TPD measurement was carried out in a similar fashion as IPA-TPD. The weight loss from $300{ }^{\circ} \mathrm{C}$ and $400{ }^{\circ} \mathrm{C}$ was used to determine the Brønsted acid site density on the external surface of the catalyst.

The morphology of the catalyst was examined by transmission electron microscopy (TEM, JEOL 2000FX). The zeolite powder was transferred into ethanol to produce a dilute suspension by sonication for $10 \mathrm{~min}$. Subsequently, one drop of the suspension was pipetted onto a standard holey carbon-coated TEM grid. After drying it at room temperature, the grid was transferred directly into the TEM instrument operated at an accelerating voltage of $200 \mathrm{kV}$.

\subsection{CFP of cellulose and miscanthus using hierarchical MFI zeolites}

Pyrolysis experiments were performed using a CDS Analytical Pyroprobe 5200 pyrolysis gas chromatography system (PyGC). Cellulose is a major component of lignocellulosic biomass (typically between 23-32 wt.\%) [38]; thus, $\alpha$-Cellulose (Sigma Aldrich) was chosen as a representative model biomass compound. Miscanthus $x$ giganteus is an attractive biomass energy crop due to ease of growth and cultivation and high calorific value [29], and was chosen to represent a realistic biomass source. Experimental results from non-catalytic (thermal) pyrolysis can be found in the Supplementary Information.

The pyrolysis procedure is very similar to that of a previous work [39]. Catalyst/biomass mixture $(5 \mathrm{mg})$ were loaded into a quartz microreactor, which was then placed in a computer 
automated resistively heated coil. Pyrolysis was performed at a set point of $600{ }^{\circ} \mathrm{C}$ for $20 \mathrm{~s}$ under pure Ar flow of $30 \mathrm{sccm}$. Condensable products were analyzed using a gas chromatograph mass spectrometer (GC-MS, Agilent 6890 GC with 5973N MS), and permanent gases were analyzed via an online MS (Agilent 5975C), with a gas sampling attachment (Diablo Analytical). More detailed information about the analysis methods, GC hardware and quantification can be found in the supplementary information. Solid yield was determined by oxidation of any remaining residue in the microreactor in pure $\mathrm{O}_{2}$ at $900{ }^{\circ} \mathrm{C}$ and integration of the $\mathrm{CO}_{2}$ and $\mathrm{CO}$ signals measured by the MS. Because water is difficult to quantify in the PyGC, the total carbon balance was calculated in lieu of a mass balance, and all yields reported were measured relative to moles of atomic carbon in the feed. Each experiment was performed in at least triplicate to ensure precision.

\section{Results}

\subsection{Material Characterization}

\subsubsection{Structural and textural properties}

Characterization of each material highlights the structural and chemical properties that are impacted by each preparation strategy. The crystallinity and textural properties of the materials were investigated using TEM. Figure 1 shows micrographs of the (A) MFI-Pa, (B) MFI-SA-Mild, (C) MFI-DS-Mild, (D) MFI-100nm, and (E) MFI-Meso materials. MFI-Pa has a well-defined ordered crystal structure, with no voids or cavities. The MFI-DS-Mild material has clear cavities in the crystal, and many of the cavities appear to originate at the surface or edge of the crystal. The MFI-SA-Mild material appears to have fewer, slightly smaller size mesopores, compared to the MFI-DS-Mild material. None of the mesopores seem to extend to the edge of the particle, which may be a result of silica reassembly around the surfactant during the post-synthetic treatment. MFI-100nm is formed from an agglomeration of round crystals with a wellcontrolled diameter of $100 \mathrm{~nm}$. The MFI-Meso zeolite is composed of ordered agglomerated rectangular primary crystals, and clear interstitial cavities are visible through the center of the secondary particle. When comparing the materials from the top-down and bottom-up series, it 
appears that the desilicated zeolite has the most accessible mesopores, which originate at the surface and are moderate in size and quantity.

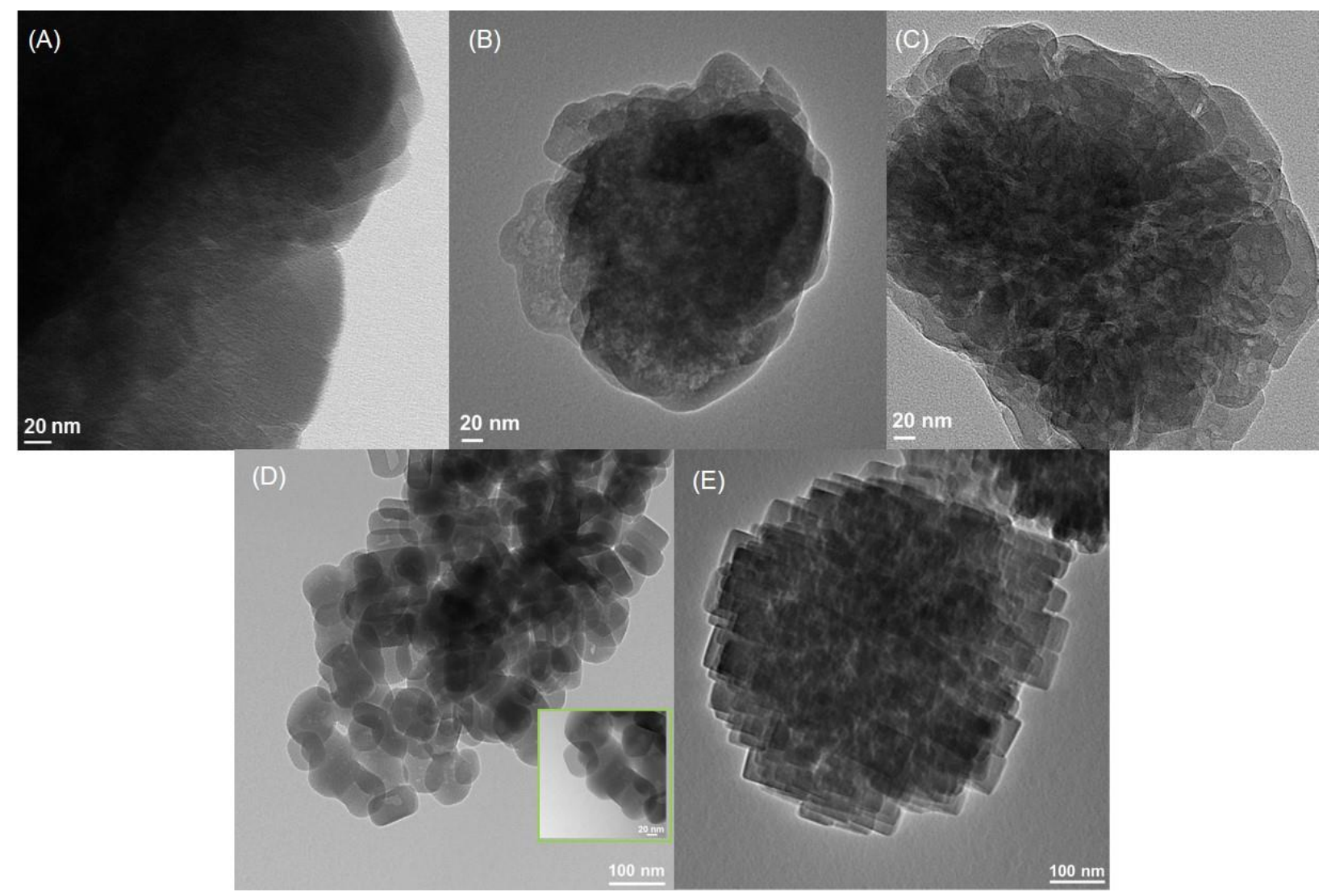

Figure 1. Transmission electron micrographs of (A) a commercial ZSM-5 (MFI-Pa), (B) ZSM-5 treated with $\mathrm{NaOH}$ and surfactant (MFI-SA-Mild), (C) ZSM-5 treated with NaOH alone (MFIDS-Mild), (D) $100 \mathrm{~nm}$ microporous ZSM-5 crystals (MFI-100nm), and (E) Mesoporous MFI zeolite (MFI-Meso).

The crystal structure of each material was confirmed by powder XRD (Figure 2). The materials created with the bottom-up techniques very clearly exhibit the characteristic MFI diffraction pattern. The relative crystallinity of the materials (Table 1) created with top-down approaches was calculated from the integrated intensity between the angles $2 \theta$ of $23-25^{\circ}$, and normalized to the MFI-Pa material. Both the MFI-DS-Mild and MFI-SA-Mild materials retained over 99\% of the crystal structure. The severe alkaline treatment from the MFI-DS-Strong (85.7\% crystallinity) 
and MFI-SA-Strong (88.1\% crystallinity) materials resulted in a decrease in crystallinity, although the addition of surfactant seems to have better protected the crystal integrity.

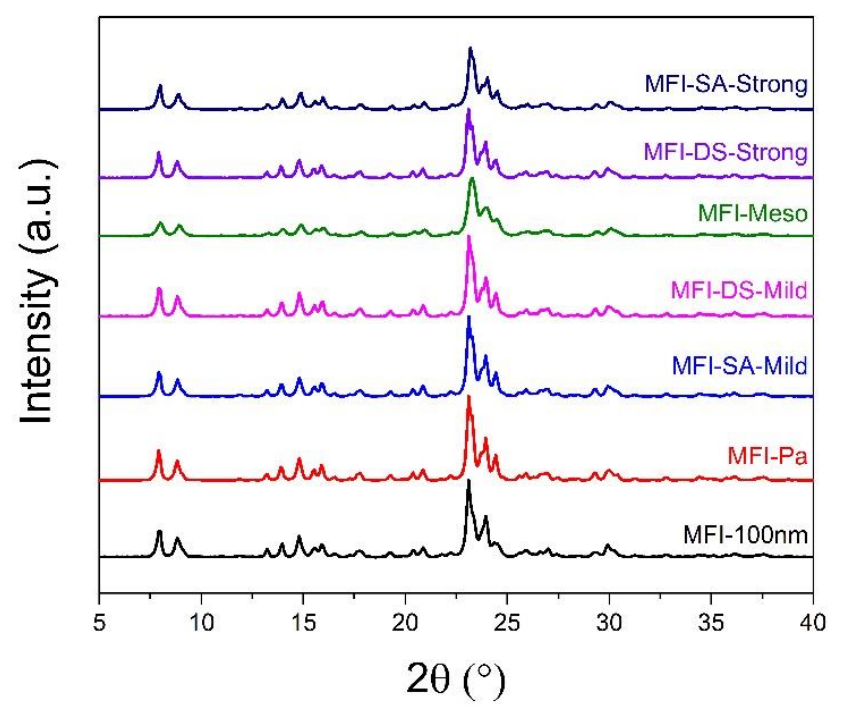

Figure 2. X-ray diffractograms of MFI parent and mesoporous catalysts prepared using bottomup and top-down methods.

The $\mathrm{N}_{2}$ sorption isotherms for each zeolite are given in Figure 3 (A). The MFI-100nm zeolite exhibited a type II isotherm (IUPAC standard), with almost no hysteresis, and a sharp increase at high $\mathrm{P} / \mathrm{P}_{\mathrm{o}}$, most likely due to macropores arising from the void space between the randomly aggregated $100 \mathrm{~nm}$ MFI crystals. All the other material isotherms were a mixture of type I and type IV with some variation in the hysteresis loop. The MFI-SA-Mild and MFI-SA-Strong materials exhibited type $\mathrm{H} 2$ hysteresis loops, traditionally referred to as 'ink-bottle' type mesopores. The hysteresis loops of the MFI-Pa, MFI-DS-Mild and MFI-DS-Strong materials were closer to type $\mathrm{H} 4$ hysteresis, with almost parallel adsorption and desorption branches, indicating more narrow slit-like pores [40]. Finally, the MFI-Meso hysteresis loop was somewhere between $\mathrm{H} 2$ and $\mathrm{H} 4$, possibly a result of the untemplated interstitial mesopores [22]. The BET surface area increased upon the introduction of mesoporosity, as presented in Table 1. The micropore volume varied from $0.14 \mathrm{~cm}^{3} \mathrm{~g}^{-1}$ (MFI-Pa) to $0.09 \mathrm{~cm}^{3} \mathrm{~g}^{-1}$ (MFI-DSStrong), a 35\% reduction. The mesopore volume had much greater variation, between $0.07 \mathrm{~cm}^{3}$ 
$\mathrm{g}^{-1}$ (MFI-100nm) and $0.33 \mathrm{~cm}^{3} \mathrm{~g}^{-1}$ (MFI-SA-Strong). The external surface area of the catalyst also increased with increasing mesoporosity. Modification via the desilication method introduced slightly greater external surface area than desilication in the presence of surfactant.
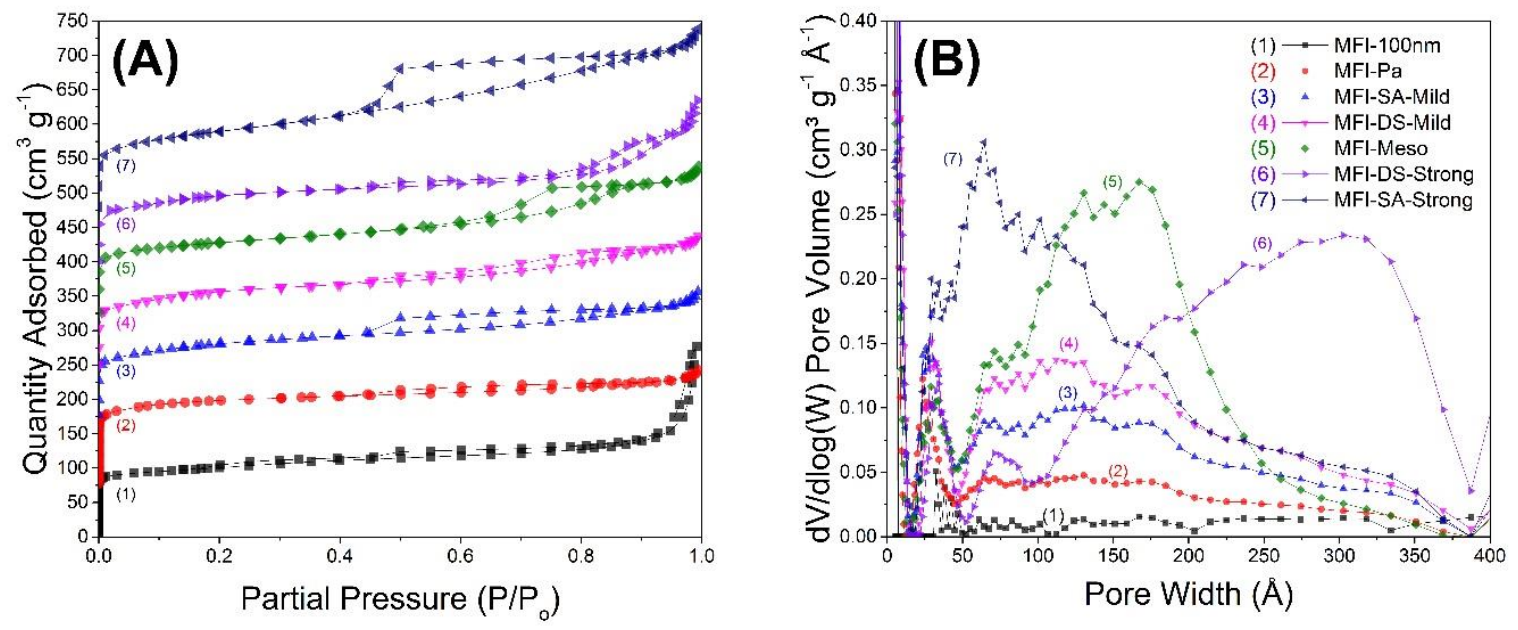

Figure 3. (A) $\mathrm{N}_{2}$ sorption isotherms of each material: (1) MFI-100nm, (2) MFI-Pa, (3) MFI-SAMild, (4) MFI-DS-Mild, (5) MFI-Meso, (6) MFI-DS-Strong, (7) MFI-SA-Strong. Isotherms are offset by a constant value of $75 \mathrm{~cm}^{3} \mathrm{~g}^{-1}$. (B) pore size distributions found using the NL-DFT model developed for $\mathrm{N}_{2}$ adsorption on $\mathrm{H}$ - form zeolites.

The materials evaluated in this study have been designed to span a wide range of mesopore volumes, while maintaining as much micropore volume as possible. The NL-DFT pore size distribution between 20 and $400 \AA$ is shown in Figure 3 (B). The MFI-100nm material exhibited the least pore volume in the mesopore region. MFI-Pa had slightly greater mesopore volume than the MFI-100nm, but not a significant amount in this region. The MFI-SA-Mild and MFI-DSMild materials both displayed a broad range of pore diameters primarily between 30 and $200 \AA$. The MFI-Meso, MFI-DS-Strong and MFI-SA-Strong materials all had significantly higher mesopore volumes. However, the pore diameter of the MFI-SA-strong material was skewed left, with the maximum volume occurring at a diameter of $40 \AA$. The MFI-Meso material exhibited a broader range of mesopore diameters, with a maximum volume occurring at a diameter of about $110 \AA$. The MFI-DS-Strong material pore volume trend was skewed right, with the maximum pore volume occurring at a pore diameter of approximately $300 \AA$. 
Table 1. Textural properties of each zeolite

\begin{tabular}{|c|c|c|c|c|c|c|c|}
\hline Material & $\begin{array}{c}\text { Preparation } \\
\text { Strategy }\end{array}$ & $\begin{array}{c}\text { Total } \\
\text { Surface } \\
\text { Area }^{1} \\
\left(\mathrm{~m}^{2} / \mathrm{g}\right)\end{array}$ & $\begin{array}{c}\text { External } \\
\text { Surface } \\
\text { Area }^{2} \\
\left(\mathrm{~m}^{2} / \mathrm{g}\right) \\
\end{array}$ & $\begin{array}{c}\text { Total } \\
\text { Pore } \\
\text { Volume }^{3} \\
\left(\mathrm{~cm}^{3} / \mathrm{g}\right) \\
\end{array}$ & $\begin{array}{l}V_{\text {micro }}^{2} \\
\left(\mathrm{~cm}^{3} / \mathrm{g}\right)\end{array}$ & $\begin{array}{c}V_{\text {meso }}{ }^{4} \\
\left(\mathrm{~cm}^{3} / \mathrm{g}\right)\end{array}$ & $\begin{array}{c}\text { XRD } \\
\text { Relative } \\
\text { Intensity } \\
\% \\
\end{array}$ \\
\hline MFI-100nm & Bottom-up & 342 & 126 & 0.53 & 0.10 & $0.07^{*}$ & 95.7 \\
\hline MFI-Pa & Commercial & 419 & 126 & 0.25 & 0.14 & 0.12 & 100.0 \\
\hline MFI-SA-Mild & Top-down & 455 & 210 & 0.31 & 0.11 & 0.20 & 99.1 \\
\hline MFI-DS-Mild & Top-down & 456 & 229 & 0.32 & 0.10 & 0.22 & 99.5 \\
\hline MFI-Meso & Bottom-up & 437 & 170 & 0.36 & 0.12 & 0.24 & 91.8 \\
\hline MFI-DS-Strong & Top-down & 422 & 221 & 0.37 & 0.09 & 0.28 & 85.7 \\
\hline MFI-SA-Strong & Top-down & 484 & 267 & 0.43 & 0.10 & 0.33 & 88.1 \\
\hline
\end{tabular}

\subsubsection{Acidity}

The bulk Si/Al ratio of each material was determined using ICP-OES, and ranged from 19.1 (MFI-Meso) to 40.6 (MFI-Pa). Of the top-down series, the MFI-SA-Mild material retained the most $\mathrm{Si}$, with only an $8.4 \%$ reduction in $\mathrm{Si} / \mathrm{Al}$ ratio. Mild desilication and desilication with surfactant resulted in higher retention of $\mathrm{Si}$, compared to the stronger treatments. The $\mathrm{Si} / \mathrm{Al}$ ratio of both MFI-100nm (30.4) and MFI-Meso (19.1) was relatively low, indicating potentially higher zeolite acidity. One challenge of the method used to create the MFI-Meso material is maintaining the $\mathrm{Si} / \mathrm{Al}$ ratio between the slurry and final product.

Figure 4 (A) shows the DRIFTs spectra of the $-\mathrm{OH}$ stretching region of each catalyst. The peak at $3610 \mathrm{~cm}^{-1}$ is indicative of Brønsted acid sites [19], whereas the peak at $3740 \mathrm{~cm}^{-1}$ corresponds to external terminal silanol groups of MFI framework zeolites [41]. The intensity of the peak at $3610 \mathrm{~cm}^{-1}$ of the MFI-SA-Mild and MFI-DS-Mild zeolites was comparable to the MFI-Pa. The same peak was about $10 \%$ lower in intensity for the MFI-DS-Strong material, indicating a slight decrease in Brønsted acidity. 

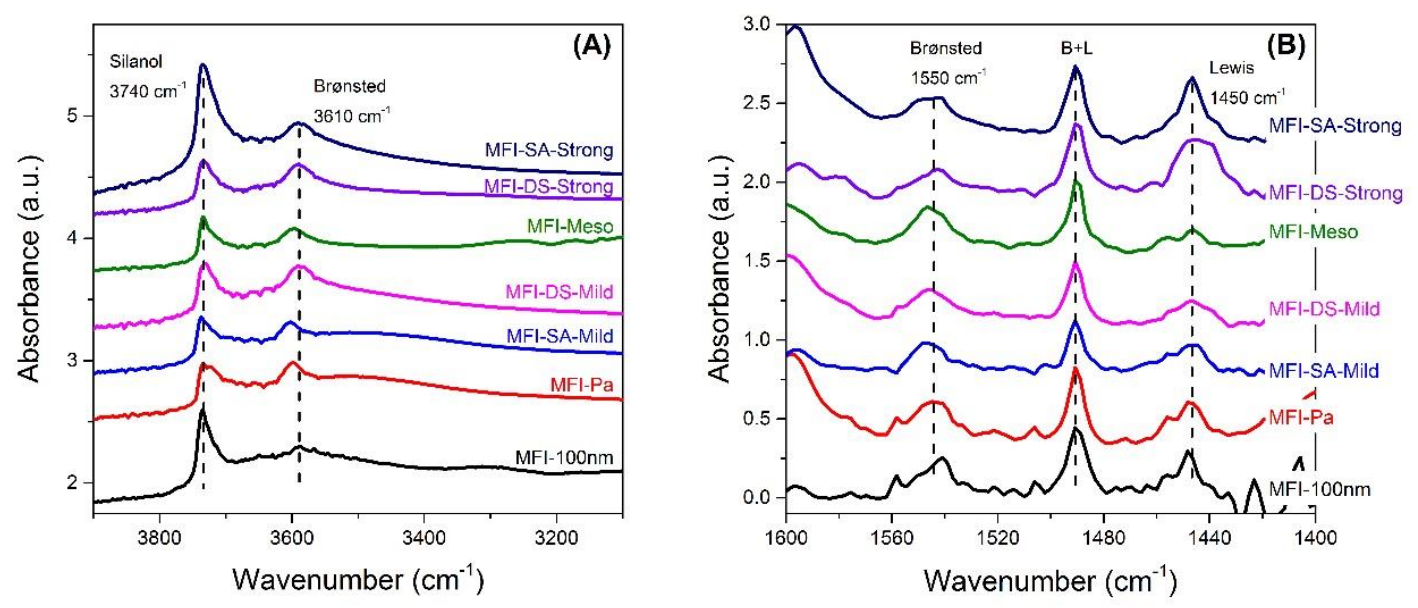

Figure 4. (A) DRIFTs spectra of each material in the $-\mathrm{OH}$ stretching region and (B) following pyridine adsorption.

All zeolites tailored using top-down methods exhibited increased intensity of the peak at 3740 $\mathrm{cm}^{-1}$, indicating that terminal silanol groups on the zeolite external surface were created by both top-down methods. The intensity of this peak was greater than the parent by $13 \%$ and $115 \%$, for MFI-SA-Mild and MFI-SA-Strong, respectively. This increase was also observed in the desilicated materials, but to a lesser extent. These results further indicate that when surfactant is present, the silica removed from the framework by the alkaline treatment recrystallized at the surface, forming external terminal silanol groups. A similar phenomenon has been reported by Schmidt et al. [42] when comparing desilication and desilication with surfactant reassembly.

In order to further investigate the Brønsted and Lewis acidity of each sample, FTIR spectra were collected after the adsorption of pyridine, which are displayed in Figure 4 (B). The relative amount of Brønsted and Lewis acidity can be found from the intensity of the peaks at $1550 \mathrm{~cm}^{-1}$ and $1450 \mathrm{~cm}^{-1}$, and corrected using the extinction coefficients of 1.67 and 2.22, respectively [43]. The Brønsted/Lewis acid ratio of each material, determined from DRIFTs spectra, are presented in Table 2. Materials created with bottom-up methods had significantly higher Brønsted acidity compared to Lewis acidity. The MFI-SA-Mild and MFI-DS-Mild zeolites exhibited slightly greater Brønsted acidity compared to Lewis acidity. But, the MFI-DS-Strong and MFI-SA-Strong materials displayed increased Lewis acidity despite the higher $\mathrm{Si} / \mathrm{Al}$ ratio, revealing that 
concentrated strong base caused extensive leaching of framework aluminum to the extraframework, in good agreement with earlier literature [20,44,45].

The total Brønsted acidity of each zeolite, determined by IPA-TPD, is presented in Table 2. IPA binds to all active Brønsted acid sites of the catalyst, both on the external surface and in the pores [37]. The most acidic catalysts were those created using bottom-up methods, MFI-100nm and MFI-Meso. Mild base treatment resulted in slightly increased catalyst Brønsted acidity, which was consistent with the decreased $\mathrm{Si} / \mathrm{Al}$ ratio observed from ICP. The MFI-DS-Strong material had the lowest Brønsted acidity, with only $0.29 \mathrm{mmol} \mathrm{IPA/g}$ adsorbed. The MFI-SAStrong material adsorbed slightly higher amounts of IPA than the parent, demonstrating that the use of surfactant protects some framework $\mathrm{Al}$ from being extracted during treatment.

Table 2. Characterization of the acidic properties of each zeolite

\begin{tabular}{ccccc}
\hline Material & $\begin{array}{c}\text { Total } \\
\text { Brønsted } \\
\text { Acid Sites } \\
(\mathrm{mmol} / \mathrm{g})\end{array}$ & $\begin{array}{c}\text { External Brønsted } \\
\text { Acid Sites }^{2} \\
(\mathrm{mmol} / \mathrm{g})\end{array}$ & $\begin{array}{c}\text { B.A./L.A Peak Area } \\
\text { Ratio }^{3}\end{array}$ & $\begin{array}{c}\text { Si/Al } \\
\text { Ratio }^{4}\end{array}$ \\
\hline MFI-100nm & 0.50 & 0.015 & 1.86 & 30.4 \\
MFI-Pa & 0.30 & 0.061 & 1.15 & 40.6 \\
MFI-SA-Mild & 0.34 & 0.032 & 1.37 & 37.2 \\
MFI-DS-Mild & 0.31 & 0.069 & 1.22 & 36.2 \\
MFI-Meso & 0.55 & 0.039 & 2.33 & 19.1 \\
MFI-DS-Strong & 0.29 & 0.072 & 0.66 & 33.2 \\
MFI-SA-Strong & 0.34 & 0.057 & 0.60 & 29.1 \\
\hline
\end{tabular}

Determined By: ${ }^{1} \mathrm{IPA}-\mathrm{TPD},{ }^{2} \mathrm{CLD}-\mathrm{TPD},{ }^{3} \mathrm{Py}-\mathrm{IR},{ }^{4} \mathrm{ICP}-\mathrm{OES}$

Materials were also probed for external surface Brønsted acidity using CLD-TPD. CLD is a relatively bulky molecule (critical diameter of $7.4 \AA$ ), and theoretically only accessible to Brønsted acid sites at external surface of zeolites with MFI topology (pore openings of 5.5-5.6 Å) [46]. Of the MFI zeolites prepared for this study, the MFI-DS-Strong material adsorbed the most collidine $\left(0.072 \mathrm{mmol} \mathrm{g}^{-1}\right)$, whereas the MFI-100nm adsorbed the least $\left(0.015 \mathrm{mmol} \mathrm{g}^{-1}\right)$, as 
shown in Table 2. This indicates that the majority of the Brønsted acid sites of the MFI-100nm material are located within the zeolite micropores. Materials created by desilication adsorbed more CLD than the MFI-Pa, but those created with surfactant present adsorbed less than the parent. Moreover, the MFI-Meso material adsorbed relatively little CLD (0.039 $\left.\mathrm{mmol} \mathrm{g}^{-1}\right)$ compared to the other mesoporous materials, an indication that this method creates fewer external Brønsted acid sites. This is particularly true when comparing to desilication, where silica is leached from the surface. Moreover, it indicates that desilication greatly improves accessibility of bulky molecules, such as CLD, to zeolite acid sites [14], whereas the acid sites of the MFI-Meso material are primarily located in the catalyst micropores. Additionally, there is almost a direct correlation between the catalyst external surface area and catalyst external acidity measured by CLD-TPD. An identical correlation was noted by Puértolas et al [30].

Interestingly, when the Brønsted/Lewis acid ratio estimated from pyridine adsorption is taken into consideration along with the TPD measurements, two different trends are observed when comparing top-down zeolites to the parent material: (1) increase in the Brønsted/Lewis acid ratio under mild conditions, and (2) decrease in the Brønsted/Lewis acid ratio under strong conditions. One possible explanation for this trend is that Si seems to be extracted from external surfaces rather than the bulk of the sample. Some Brønsted acid sites may have been removed, along with silica leached from the external surfaces. The extra-framework alumina was partially removed by acid treatment after mild desilication, thereby decreasing the concentration of Lewis acid sites, in accordance with previous findings [45,47]. In this case, it seems that the etching of zeolite by $\mathrm{OH}^{-}$starts on the exterior surface. Under strong basic environments, desilication seems to occur in both the external surface and bulk. A high degree of extracted Al caused by a concentrated strong base can be re-precipitated on the surface to give extraframework Al (Lewis acid sites) [10,20,44,45,48]. Furthermore, from the CLD-TPD results, the mesoporous ZSM-5 samples created with surfactant mediated desilication exhibited lower external Brønsted acid site concentrations than both the parent and desilicated samples. One possible explanation for the lower surface acidity in the -SA designated materials may be the simultaneous re-deposition of both $\mathrm{Si}$ formed around micelles in addition to extracted 
aluminum species on the material surface. This could result in more terminal silanol groups, increased Lewis acidity and fewer surface Brønsted acid sites.

\subsection{Biomass CFP with hierarchical MFI catalysts}

PyGC was used to determine the effects of hierarchical ZSM-5 catalysts on the CFP product distribution. For thoroughness, the pyrolysis of miscanthus was performed with each catalyst at three different catalyst to biomass $(\mathrm{C} / \mathrm{B})$ ratios. The carbon yields to solid (coke and char), permanent gas and bio-oil, as well as the overall carbon yield for these experiments are displayed in the Supplementary Information (Figure S1). Only experiments with a carbon balance of $100 \pm 10 \%$ were accepted. CFP with the MFI-DS-Mild material resulted in the highest bio-oil yields at C/B ratios of both 5 and 10. More detailed analyses and product breakdowns for both cellulose and miscanthus CFP at a constant C/B ratio of 5 follow in the next two sections.

\subsubsection{CFP of cellulose}

The complete product distribution from cellulose CFP at a C/B ratio of 5 is depicted in Table 3. The data is arranged in order of increasing mesopore volume. The liquid yield increased with mesopore volume, from about 16 \% (MFI-100nm) up to a maximum of around 29 \% (MFI-DSMild), then decreased slightly. The lumped permanent gas yield followed no apparent trend, and the solid yield decreased with increasing mesopore volume to a minimum (MFI-DS-Mild), then increased slightly.

The permanent gas product distribution from cellulose CFP is also given in Table 3. CO carbon yield increased slightly with mesopore volume, up to a maximum of about $23 \%$, then decreased for CFP with the -Strong designated zeolites. $\mathrm{CO}_{2}$ yield remained mostly constant with mesopore volume. However, CFP with the MFI-DS-Strong produced significantly less $\mathrm{CO}_{2}$. Only small amounts of methane and propylene were detected, with methane and olefins yield totaling a maximum of $3.1 \%$ carbon. 
Table 3. Product distribution for CFP of cellulose at C/B ratio of 5.

\begin{tabular}{|c|c|c|c|c|c|c|c|}
\hline \multirow{2}{*}{$\begin{array}{c}\text { Carbon Yield } \\
(\%)\end{array}$} & \multirow{2}{*}{$\begin{array}{l}\text { Catalyst } \\
\text { MFI-100nm }\end{array}$} & \multirow[b]{2}{*}{ MFI-Pa } & \multirow[b]{2}{*}{$\begin{array}{l}\text { MFI-SA- } \\
\text { Mild }\end{array}$} & \multirow[b]{2}{*}{$\begin{array}{l}\text { MFI-DS- } \\
\text { Mild }\end{array}$} & \multirow[b]{2}{*}{ MFI-Meso } & \multirow[b]{2}{*}{$\begin{array}{l}\text { MFI-DS- } \\
\text { Strong }\end{array}$} & \multirow[b]{2}{*}{$\begin{array}{l}\text { MFI-SA- } \\
\text { Strong }\end{array}$} \\
\hline & & & & & & & \\
\hline \multicolumn{8}{|l|}{ Liquid Products } \\
\hline Benzene & $1.5 \pm 0.1$ & $2.1 \pm 0.2$ & $2.1 \pm 0.2$ & $2.1 \pm 0.1$ & $2.6 \pm 0.2$ & $2.3 \pm 0.3$ & $2.7 \pm 0.1$ \\
\hline Toluene & $2.4 \pm 0.1$ & $4.1 \pm 0.2$ & $4.1 \pm 0.3$ & $4.5 \pm 0.2$ & $4.7 \pm 0.2$ & $4.1 \pm 0.4$ & $4.3 \pm 0.1$ \\
\hline Xylenes & $1.3 \pm 0.04$ & $3.0 \pm 0.3$ & $3.1 \pm 0.2$ & $3.6 \pm 0.2$ & $3.6 \pm 0.2$ & $2.9 \pm 0.3$ & $3.4 \pm 0.1$ \\
\hline Alkyl Benzenes & $2.1 \pm 0.2$ & $3.7 \pm 0.6$ & $3.8 \pm 0.6$ & $4.9 \pm 0.6$ & $4.2 \pm 0.5$ & $2.9 \pm 0.3$ & $4.5 \pm 0.4$ \\
\hline Indenes & $2.5 \pm 0.5$ & $3.0 \pm 0.4$ & $3.7 \pm 0.2$ & $3.6 \pm 0.4$ & $3.2 \pm 0.3$ & $3.7 \pm 0.8$ & $3.2 \pm 0.3$ \\
\hline Naphthalenes & $2.6 \pm 0.2$ & $4.2 \pm 0.3$ & $4.5 \pm 0.4$ & $6.1 \pm 0.2$ & $6.2 \pm 0.3$ & $5.5 \pm 0.5$ & $4.8 \pm 0.2$ \\
\hline PAHs & $0.4 \pm 0.04$ & $0.4 \pm 0.1$ & $0.6 \pm 0.3$ & $0.8 \pm 0.04$ & $1.6 \pm 0.3$ & $1.4 \pm 0.4$ & $1.6 \pm 0.1$ \\
\hline Phenols & $2.4 \pm 0.04$ & $2.1 \pm 0.1$ & $2.4 \pm 0.3$ & $2.5 \pm 0.2$ & $1.6 \pm 0.1$ & $2.8 \pm 0.6$ & $2.4 \pm 0.3$ \\
\hline Benzofurans & $0.6 \pm 0.04$ & $0.6 \pm 0.09$ & $0.7 \pm 0.3$ & $0.8 \pm 0.01$ & $0.4 \pm 0.04$ & $1.0 \pm 0.28$ & $0.8 \pm 0.08$ \\
\hline Other Oxy. & $0.4 \pm 0.2$ & $0.3 \pm 0.05$ & $0.2 \pm 0.2$ & $0.1 \pm 0.02$ & $0.1 \pm 0.1$ & $0.8 \pm 0.1$ & $0.8 \pm 0.3$ \\
\hline Total & $16.1 \pm 0.7$ & $23.4 \pm 1.1$ & $25.3 \pm 2.3$ & $29.1 \pm 0.9$ & $28.2 \pm 1.0$ & $27.4 \pm 3.4$ & $28.4 \pm 0.3$ \\
\hline \multicolumn{8}{|c|}{ Permanent Gases } \\
\hline $\mathrm{CO}$ & $18.7 \pm 0.5$ & $20.9 \pm 1.2$ & $21.6 \pm 0.9$ & $21.2 \pm 1.5$ & $23.1 \pm 1.4$ & $18.1 \pm 0.2$ & $18.7 \pm 0.5$ \\
\hline $\mathrm{CO}_{2}$ & $6.9 \pm 0.4$ & $7.2 \pm 1.5$ & $7.0 \pm 0.5$ & $6.6 \pm 0.3$ & $7.3 \pm 0.2$ & $4.8 \pm 0.2$ & $6.9 \pm 0.4$ \\
\hline $\mathrm{CH}_{4}$ & $1.8 \pm 0.2$ & $1.1 \pm 0.3$ & $0.7 \pm 0.3$ & $0.8 \pm 0.1$ & $0.8 \pm 0.2$ & $2.0 \pm 0.1$ & $1.8 \pm 0.2$ \\
\hline $\mathrm{C}_{3} \mathrm{H}_{6}$ & $0.8 \pm 0.1$ & $0.4 \pm 0.1$ & $0.4 \pm 0.2$ & $0.8 \pm 0.1$ & $0.6 \pm 0.1$ & $1.1 \pm 0.7$ & $0.8 \pm 0.1$ \\
\hline Total & $27.2 \pm 2.4$ & $29.7 \pm 2.1$ & $29.6 \pm 1.2$ & $29.3 \pm 1.3$ & $31.9 \pm 1.5$ & $26 \pm 1.1$ & $28.2 \pm 0.2$ \\
\hline Coke and Char & $54.1 \pm 4.3$ & $48.4 \pm 2.1$ & $46.8 \pm 2.6$ & $43.4 \pm 2.7$ & $46.4 \pm 3.6$ & $46.5 \pm 0.5$ & $46.5 \pm 1.7$ \\
\hline Total Yield & $97.4 \pm 4.2$ & $101.2 \pm 3.3$ & $101.2 \pm 5.7$ & $101.7 \pm 1.6$ & $102.1 \pm 3.0$ & $96.9 \pm 3.9$ & $103.2 \pm 1.7$ \\
\hline
\end{tabular}

Reaction Conditions: Temperature: $600{ }^{\circ} \mathrm{C}$, Reaction Time: $20 \mathrm{~s}$, Loading: $5 \mathrm{mg}$ total; $5 \mathrm{mg}$ catalyst/mg cellulose

The bio-oil composition was further broken down into individual categories in Table 3. The yields to benzene, toluene and xylenes all increased with increasing mesopore volume. The yields to alkyl benzenes, which include mono- and di- substituted aromatic compounds, increased to the point of MFI-DS-Mild, and then decreased with the MFI-Meso catalyst. Alkyl aromatics with a higher degree of substitution and longer alkyl chains were observed as mesopore volume increased. The indenes category, which includes indene, indane and substituted derivatives, also increased to a maximum, which occured at the MFI-SA-Mild material. Naphthalenes, including mono- and di-substituted methyl- and ethyl- naphthalenes 
all increased to a maximum as well, but the greatest value occurred for CFP with the MFI-Meso material. PAHs, which include any compound with three or more aromatic rings, increased significantly with increasing mesopore volume, and CFP with the three most mesoporous catalysts produced about $1.5 \%$ carbon yield to PAHs. Relatively few oxygenates were detected, mostly due to the sufficiently acidic nature of all catalysts. The most oxygenates for cellulose CFP were detected from the MFI-DS-Strong material, and the fewest from the MFI-Meso, which was mainly attributed to the relatively low and high acidity of those catalysts, respectively.

\subsubsection{CFP of Miscanthus $x$ giganteus}

The same analysis was performed for CFP of miscanthus under identical conditions, and is presented in Table 4, again in order of increasing mesopore volume. The liquid yield increased with increasing mesopore volume, reaching a maximum at $29.6 \%$, with the MFI-DS-Mild material. The permanent gas yield followed no particular trend, although the maximum occurred at $26 \%$ from CFP with the MFI-Pa material, and the minimum was approximately $22 \%$ (MFI-SA-Strong). As in the case of cellulose, the solid yield decreased with increasing mesoporosity until the MFI-DS-Mild material was reached, at which point it increased.

CFP with the MFI-SA-Strong, MFI-DS-Strong and MFI-100nm materials resulted in relatively low $\mathrm{CO}$ yields compared to CFP with the other materials. The $\mathrm{CO}_{2}$ yield was also slightly lower for those three materials. Methane and propylene yields were approximately equivalent for all materials tested.

The bio-oil product distribution for CFP of miscanthus with each catalyst is also presented in Table 4. A slight increase in benzene, toluene and xylenes (BTX) was again observed with increasing mesoporosity. A clear maximum in the production of alkyl benzenes and indenes was also evident for CFP with the MFI-DS-Mild material. CFP with the MFI-Meso material produced larger molecules, such as naphthalenes and PAHs. CFP with the MFI-100nm and MFI-DS-Strong materials produced significantly higher amounts of phenols, whereas similar amounts of phenols were created during cellulose CFP with both materials. Phenols are primarily a result of lignin decomposition at high temperature [7]. Lignin is not present during 
cellulose pyrolysis, but comprises a significant fraction of miscanthus, therefore higher phenol yields are expected from CFP with miscanthus compared to cellulose. The elevated presence of phenols from these two materials could be a result of shape exclusion from the MFI-100nm material or lower acidity for the MFI-DS-Strong. Similar amounts of benzofurans and other oxygenates were produced from CFP with all materials.

Table 4. Product distribution for CFP of miscanthus at C/B ratio of 5.

\begin{tabular}{|c|c|c|c|c|c|c|c|}
\hline \multirow{2}{*}{$\begin{array}{c}\text { Carbon Yield } \\
(\%) \\
\end{array}$} & \multirow{2}{*}{$\begin{array}{l}\text { Catalyst } \\
\text { MFI-100nm } \\
\end{array}$} & \multirow[b]{2}{*}{ MFI-Pa } & \multirow[b]{2}{*}{$\begin{array}{l}\text { MFI-SA- } \\
\text { Mild } \\
\end{array}$} & \multirow[b]{2}{*}{$\begin{array}{l}\text { MFI-DS- } \\
\text { Mild } \\
\end{array}$} & \multirow[b]{2}{*}{ MFI-Meso } & \multirow[b]{2}{*}{$\begin{array}{l}\text { MFI-DS- } \\
\text { Strong } \\
\end{array}$} & \multirow[b]{2}{*}{$\begin{array}{c}\text { MFI-SA- } \\
\text { Strong } \\
\end{array}$} \\
\hline & & & & & & & \\
\hline \multicolumn{8}{|l|}{ Liquid Products } \\
\hline Benzene & $1.4 \pm 0.3$ & $1.4 \pm 0.2$ & $1.5 \pm 0.2$ & $1.6 \pm 0.2$ & $1.5 \pm 0.1$ & $1.6 \pm 0.4$ & $1.2 \pm 0.01$ \\
\hline Toluene & $2.6 \pm 0.3$ & $3.6 \pm 0.3$ & $3.8 \pm 0.3$ & $3.7 \pm 0.6$ & $3.8 \pm 0.1$ & $4.3 \pm 0.2$ & $3.3 \pm 0.1$ \\
\hline Xylenes & $1.9 \pm 0.2$ & $3.6 \pm 0.4$ & $3.9 \pm 0.2$ & $3.9 \pm 0.5$ & $3.6 \pm 0.3$ & $3.9 \pm 0.3$ & $3.5 \pm 0.1$ \\
\hline Alkyl Benzenes & $2.8 \pm 0.3$ & $4.1 \pm 0.4$ & $4.4 \pm 0.2$ & $4.6 \pm 0.2$ & $3.7 \pm 0.1$ & $3.7 \pm 0.4$ & $4 \pm 0.2$ \\
\hline Indenes & $2.6 \pm 0.5$ & $3.4 \pm 1.0$ & $3.8 \pm 0.2$ & $5.2 \pm 0.2$ & $4.2 \pm 0.2$ & $4 \pm 0.4$ & $3.8 \pm 0.4$ \\
\hline Naphthalenes & $2.8 \pm 0.4$ & $5.2 \pm 0.5$ & $5.8 \pm 1.0$ & $6.5 \pm 0.7$ & $6.6 \pm 1.3$ & $5.7 \pm 0.7$ & $5.4 \pm 0.3$ \\
\hline PAHs & $0.3 \pm 0.1$ & $0.4 \pm 0.2$ & $0.3 \pm 0.2$ & $0.6 \pm 0.2$ & $1.4 \pm 0.5$ & $1.1 \pm 0.1$ & $1.2 \pm 0.1$ \\
\hline Phenols & $4.9 \pm 0.7$ & $2.5 \pm 0.6$ & $2.2 \pm 0.5$ & $2.1 \pm 0.7$ & $1.4 \pm 0.1$ & $3.5 \pm 0.1$ & $1.7 \pm 0.2$ \\
\hline Benzofurans & $0.4 \pm 0.1$ & $0.5 \pm 0.1$ & $0.3 \pm 0.05$ & $0.5 \pm 0.3$ & $0.2 \pm 0.01$ & $0.7 \pm 0.2$ & $0.3 \pm 0.1$ \\
\hline Other Oxy. & $0.7 \pm 0.4$ & $0.1 \pm 0.1$ & $0.1 \pm 0.1$ & $0.3 \pm 0.3$ & $0.1 \pm 0.1$ & $0.5 \pm 0.1$ & $0.2 \pm 0.1$ \\
\hline Total Liquids & $20.5 \pm 2.7$ & $24.9 \pm 2.0$ & $26 \pm 1.1$ & $29.1 \pm 2.4$ & $26.5 \pm 2.8$ & $29 \pm 2.0$ & $24.6 \pm 0.7$ \\
\hline \multicolumn{8}{|l|}{ Permanent Gas } \\
\hline $\mathrm{CO}$ & $14.1 \pm 1.1$ & $16.8 \pm 2.8$ & $15.6 \pm 1.6$ & $16.1 \pm 1.5$ & $15.8 \pm 0.5$ & $15.1 \pm 0.2$ & $15 \pm 2.1$ \\
\hline $\mathrm{CO}_{2}$ & $6.3 \pm 0.2$ & $7.9 \pm 1.8$ & $7 \pm 1.1$ & $7.6 \pm 1.9$ & $7.6 \pm 1.5$ & $5.0 \pm 0.5$ & $6.2 \pm 0.3$ \\
\hline $\mathrm{CH}_{4}$ & $1.3 \pm 0.1$ & $0.8 \pm 0.2$ & $1.9 \pm 0.8$ & $1.5 \pm 0.4$ & $1.3 \pm 0.2$ & $2.3 \pm 0.1$ & $2.0 \pm 0.02$ \\
\hline $\mathrm{C}_{3} \mathrm{H}_{6}$ & $1.9 \pm 2.7$ & $0.6 \pm 1.3$ & $0.6 \pm 0.5$ & $0.3 \pm 0.1$ & $0.8 \pm 0.8$ & $0.9 \pm 0.2$ & $1.2 \pm 0.1$ \\
\hline Total Gas & $23.6 \pm 3.8$ & $26.1 \pm 3.7$ & $24.5 \pm 1.8$ & $24.9 \pm 2.7$ & $25.5 \pm 3$ & $23.3 \pm 2.7$ & $23.2 \pm 2$ \\
\hline Coke and Char & $58.2 \pm 1.4$ & $53.9 \pm 4.6$ & $49.6 \pm 3.4$ & $44.9 \pm 5.1$ & $49.3 \pm 0.5$ & $48.8 \pm 1.1$ & $51.6 \pm 2.5$ \\
\hline Carbon Yield & $100.8 \pm 2.3$ & $100 \pm 2.1$ & $95.4 \pm 7$ & $98.7 \pm 8$ & $101.4 \pm 0.2$ & $100 \pm 4.5$ & $99.3 \pm 1.4$ \\
\hline
\end{tabular}

Reaction Conditions: Temperature: $600{ }^{\circ} \mathrm{C}$, Reaction Time: $20 \mathrm{~s}$, Loading: $5 \mathrm{mg}$ total; $5 \mathrm{mg}$ catalyst $/ \mathrm{mg}$ miscanthus 


\subsection{Understanding the effects of catalyst mesoporosity on CFP}

An understanding of the mechanisms of CFP and coke formation in ZSM-5 is required prior to any analysis of the CFP product distribution. Primary products formed in the initial stages of biomass pyrolysis are mostly water and oxygenated compounds including furans, soluble sugars, carboxylic acids and phenols [49]. These compounds then enter the catalyst pores and undergo a series of acid-catalyzed deoxygenation reactions, to form aromatic hydrocarbons [50]. Coke arises from the polymerization of these large compounds until the molecule is no longer able to diffuse out of the pore structure [51], thus deactivating the catalyst by occupying active sites and blocking pores.

The goal of this study is to determine the effects of mesoporosity introduction on the product distribution for biomass CFP. It is nearly impossible to tailor zeolites with different mesopore volumes, while maintaining identical internal and external acidic properties. A wide variety of synthesis and post-synthetic modification techniques were used in this study as an attempt to try and reconcile this fact, such that the most direct comparison possible could be made. To better understand how mesoporosity affects product formation, yields to MAHs, naphthalenes, PAHs and coke/char have been plotted in Figure 5 in order of increasing catalyst mesopore volume. The same data have been plotted in order of total catalyst Brønsted acidity (determined by IPA-TPD), and are reported in the Supplemental Information (Figure S2).

Figure 5 shows the carbon yields from CFP with each catalyst and biomass to MAHs. These include compounds that have only one aromatic ring, or compounds which have an aromatic ring fused with a five-member carbon ring, primarily BTX, alkyl benzene and indene compounds. From Figure S2, there is no clear correlation between total Brønsted acidity of our materials and selectivity to products of this category, however there is a very clear relation between mesopore volume and formation of MAHs, as shown in Figure 5. There is a significant increase in the yields to compounds of this category with increasing mesoporosity, and a maximum yield is reached at a mesopore volume of about $0.22 \mathrm{~cm}^{3} \mathrm{~g}^{-1}$ (MFI-DS-Mild). 


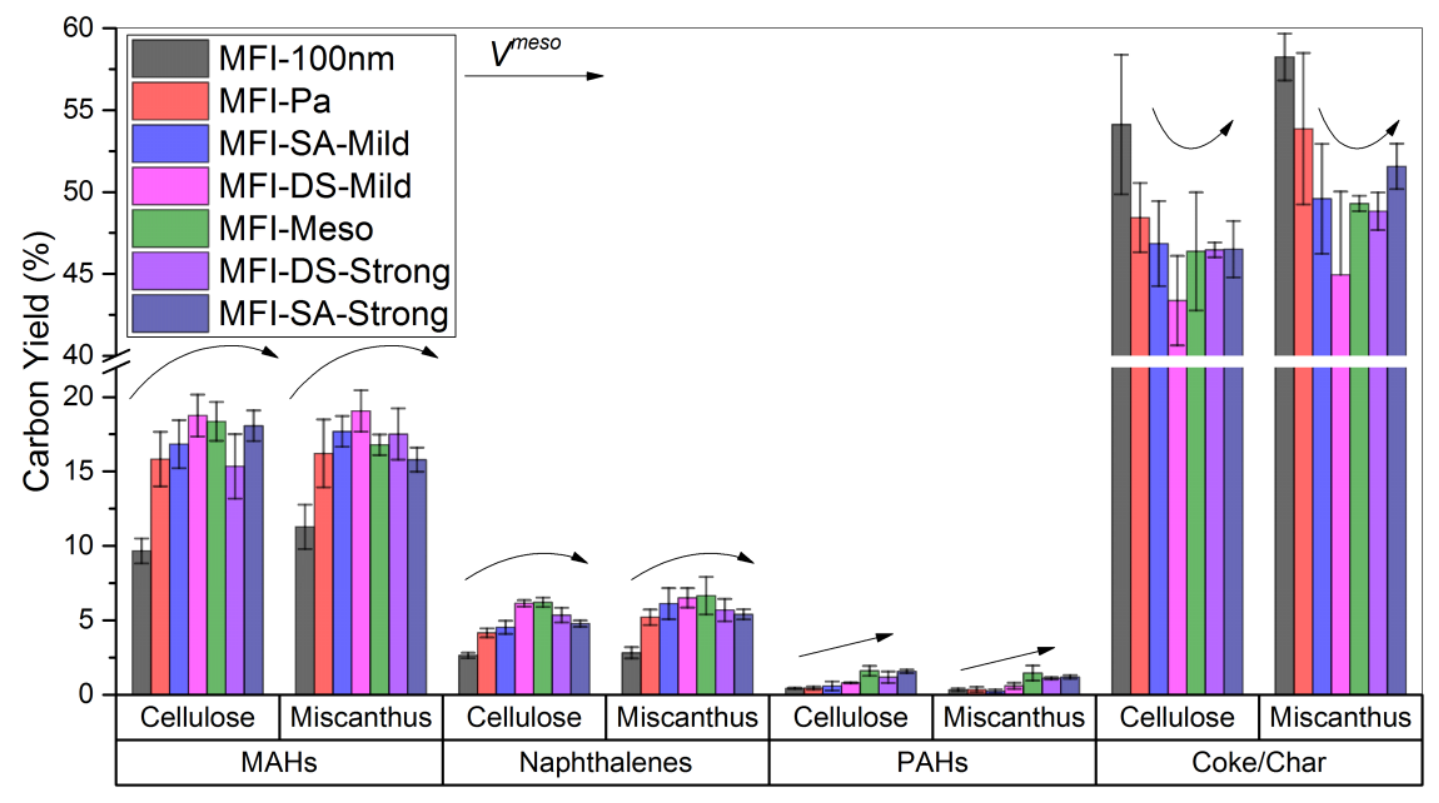

Figure 5. Lumped yields to MAHs (including BTX, alkyl benzenes and indenes), naphthalenes, PAHs and coke and char plotted in order of increasing mesopore volume. Reaction Conditions: Temperature: $600{ }^{\circ} \mathrm{C}$, Reaction Time: 20 s, Loading: $5 \mathrm{mg}$ total; $5 \mathrm{mg}$ catalyst/mg biomass

As shown in Figure 5, naphthalenes yield is also clearly tied to mesopore volume. The most naphthalenes were formed during CFP with the MFI-Meso material. Like MAH yield, naphthalenes yield also goes through a maximum, and decreases with the larger pore size materials. From Figure S2, there is no consistent correlation between total Brønsted acidity and naphthalenes yield. There is also a very clear relationship between PAH yield and mesopore volume. PAHs are defined as any molecule with more than two aromatic rings, and are the final catalytic product prior to the formation of coke [51]. As presented in Figure 5, PAH formation is clearly enhanced during CFP with the larger mesopore volume catalysts. The PAH carbon yield reaches a maximum at approximately $1.5 \%$.

Significantly less solids were formed when using the intermediate mesoporous catalysts, indicating the ideal mesopore volume for minimizing coke and char formation is $0.22 \mathrm{~cm}^{3} \mathrm{~g}^{-1}$ (MFI-DS-Mild). Additionally, the least amount of solids were formed on the catalysts with the DS designation. On the other hand, the highest amount of coke/char was produced during CFP 
with the MFI-100nm catalyst. This may be due to the combined effects of low external acidity, high internal acidity and low accessibility to catalyst active sites. Small CFP intermediates, such as furans, may enter the micropores and instantly react, followed by rapid polymerization to form coke, which results in pore blockage and further coke build-up [52]. Larger pyrolysis products, such as guiacols, may be excluded altogether or fail to crack at the catalyst surface, explaining the high phenol yields observed from miscanthus CFP.

Literature studies have shown that acidity plays a critical role on the CFP of biomass [31,53]. As mentioned above Figure S2 in the Supporting Information shows the effect of total acidity of the mesoporous materials (as determined by the IPA-TPD results) on the CFP product distribution. The mesoporous materials created by the top-down and the bottom-up approaches are clearly indicated. The materials created using the top-down techniques all exhibited very similar total Brønsted acidity, within $9 \%$ of the parent MFI-Pa. The two materials created using the bottomup method had approximately the same total Brønsted acidity, but higher compared to the topdown materials.

Focusing on the top-down materials, there was no clear conclusion on the role of acidity on the product distribution. The main difference between the top-down mesoporous materials was the acid site accessibility, which increased with increasing mesopore volume, as determined by CLD-TPD. From Figure 5, it is shown that this increased accessibility resulted in lower coke and char yield, and higher aromatics yield; with a maximum in MAH yield occurring using the MFIDS-Mild material. However, once mesopore volume became exceedingly large, aromatics were able to polymerize without the restraint of the MFI micropores, and increased PAH yields and solids (coke and char) were observed.

Focusing on the bottom-up materials, the MFI-Meso has slightly higher total acidity than the MFI-100nm. For these materials again the main difference was the accessibility of the acid sites as determined by the CLD-TPD. MFI-Meso had significantly more accessible acid sites. Consequently, and in agreement with the top-down materials, MAH and naphthalene yields were highly increased using the MFI-Meso, compared to the MFI-100nm. Due to the very different nature of preparation method, it would not be appropriate to compare the effects of 
acidity of the top-down and the bottom-up methods. Acid sites in these materials can differ not only on their number, but also on their location.

Because the primary mechanism for deoxygenation is decarbonylation, another indicator of catalyst activity is $\mathrm{CO}$ yield [31]. The $\mathrm{CO}$ yield was consistently low for both the least accessible catalyst (MFI-100nm) and least acidic catalyst (MFI-DS-Strong). It was high for the most acidic catalyst (MFI-Meso). This was expectedly accompanied by higher oxygenate yields for CFP with the MFI-100nm and MFI-DS-Strong materials and low oxygenate yields for CFP with the MFIMeso catalyst, further demonstrating the necessary balance between active site accessibility and total acidity.

\section{Discussion}

From the above analysis, some theories may be suggested about the effects of catalyst mesoporosity and acidity on product formation during CFP of biomass. Increased aromatic yields from biomass CFP with mesoporous catalysts have been well-documented in the literature. Li et al. [10] have shown a very similar maximum in aromatic yield and minimum in solid yield when comparing ZSM-5 zeolites prepared using increasing amounts of $\mathrm{NaOH}$ during desilication. Xylenes, alkyl benzenes and naphthalenes yields were all increased with increasing mesoporosity. They concluded that a mesopore volume of $0.13 \mathrm{~cm}^{3} \mathrm{~g}^{-1}$ was ideal for

production of aromatics, which is slightly less than the ideal mesopore volume of $0.22 \mathrm{~cm}^{3} \mathrm{~g}^{-1}$ in the present study. This illustrates that differences in pyrolysis process conditions such as temperature and C/B ratio, as well as catalyst acidity, must be taken into account when tailoring mesoporous catalysts, however the overall trends remain very similar to those presented here. Park et al. [27] found a similar increase in yield to alkyl benzenes when upgrading pyrolysis vapors with mesoporous MFI materials. However, they only found an increase in PAHs once the mesopore volume was exceedingly large.

A previous study [31] found significantly higher naphthalene and PAH yields when evaluating mesoporous ZSM-5 for glucose CFP, and concluded that mesoporous catalysts are ineffective due to a relaxation of shape selectivity. The catalysts in [31] had very large mesopore volumes 
$\left(0.55\right.$ and $\left.0.709 \mathrm{~cm}^{3} \mathrm{~g}^{-1}\right)$. In addition, the results of this study are, for the majority, in agreement with Puértolas et al. [30] who found that increasing mesopore volume increased aromatics yield. However, they noted no increase in PAHs upon mesopore introduction at low $\mathrm{Si} / \mathrm{Al}$ ratio, and an increase in solid (coke) yield with all mesoporous catalysts. Differences in upgrading configuration (in-situ vs. ex-situ), catalyst acidity and temperature may account for these variances.

Direct comparison between the mesoporous materials prepared with the two preparation methods (top-down and bottom-up) is not easy. However, some interesting observations can be made with respect to the effects of mesopore accessibility and acidity. As determined by the IPA-TPD and CLD-TPD measurements, mesoporous MFI prepared using the top-down methods had highly accessible mesopores with lower internal and increased external acid site density compared to their parent material (MFI-Pa). CFP using the top-down mesoporous zeolites resulted in decreased solid and increased aromatic yields, indicating that accessibility to mesopores with sufficient acidity enhances the conversion of bulky char precursors and oxygenates prior to entering the catalyst micropores. The MFI-DS-Mild material was the most effective material in terms of high MAH yield and low solid yield, because ample access to mesopores with external acid sites for cracking reactions was provided, while sufficient internal acidity was maintained for deoxygenation reactions and the production of aromatics. However, when the mesopore volume and external acid sites were highly increased, the internal acid site density became limited. In this highly mesoporous materials polymerization and condensation reactions started to dominate, increasing coke and char, PAH and oxygenates at the expense of small MAHs and napthalenes. The mesoporous materials prepared with the bottom-up methods had relatively high internal acidity and low external acidity, as indicated by the IPATPD and CLD-TPD results, respectively. Specifically, the external acidity of the MFI-100nm as measured by the CLD method was very low, and the accessibility of the internal pores and active sites was limited. This might explain the very low MAH yields and the high coke and char yields produced by the MFI-100nm. Bulky intermediate oxygenates cannot access the internal acid sites resulting in high rates of polymerization reactions and coke and char 
formation. The external acidity and pore accessibility of the MFI-Meso was higher compared to the MFI-100nm. The CFP results of the MFI-Meso indicated significantly increased yields to MAH compared to the MFI-100nm and reduced coke and char. One very interesting note is that the MFI-Meso had similar performance to the MFI-DS and MFI-SA, in terms of aromatic and solid yield, despite the differences in external surface are and pore accessibility. However, direct comparison between the mesoporous materials prepared with the two methods might not be appropriate due to the differences not only on the number of acid sites, but also the acid site location and other properties.

It also appears that as mesopore diameter grows larger, it does not affect the CFP product distribution. For example, from the NL-DFT calculation, the MFI-SA-Strong material has a relatively small average mesopore diameter (maximum mesopore volume at a pore width of 6.0 $\mathrm{nm})$, whereas the MFI-Meso material has an intermediate average mesopore diameter (maximum mesopore volume at a pore width of $16.6 \mathrm{~nm}$ ) and the MFI-DS-Strong has a relatively large average mesopore diameter (maximum mesopore volume at a pore width of 30 $\mathrm{nm})$. There was no significant difference in the size of the PAHs formed from CFP with these three materials. The primary differences were observed from the formation of intermediate-size compounds such as naphthalenes and indenes, which may or may not be considered undesirable products, depending on the bio-oil application. From this, it can be concluded that that mesopore diameter does not limit PAH formation, rather mesopore volume and surface acidity have a much larger impact.

Yu et al. [9] performed an excellent study on the role of shape selectivity in CFP of lignin using four different zeolites, namely ZSM-5, mordenite, beta and Y. They combined experimental data and quantum chemical computation calculations to conclude that the effective pore size of the zeolite at higher temperatures determines whether or not a molecule will gain access to the catalyst pores under the CFP conditions. In their study they also proved that, aside accessibility, zeolite acidity is another factor which affects biomass CFP; sufficient numbers of acid sites in the zeolite could rapidly convert oxygenates to aromatics, while a small number of acid sites would cause oxygenates to polymerize and form coke in the zeolite pores. They suggested that 
optimum catalyst design is critical for the effective conversion of biomass to aromatics and they suggested that highly acidic ZSM-5 with mesopores may be viable. The results of our study are in agreement with $\mathrm{Yu}$ et al. [9] and confirm that mesoporous ZSM-5 zeolites are effective biomass CFP catalysts. For CFP with top-down mesoporous MFI materials the present data suggests there is an optimum mesopore volume which can be introduced to provide access of the heavy oxygenates to the acid sites, where they are converted to aromatics. However, increasing the mesopore volume even more will cause the oxygenates to polymerize and form coke, due to the loss of internal acidity and shape restriction in the larger mesopores. CFP with our bottom-up mesoporous MFI materials also suggests the same conclusion.

Finally, the data and trends presented in this work are for a single type of biomass and a single model compound for one set of process variables. It must be noted that these trends may change with temperature, pyrolysis time, pyrolysis unit, configuration and feedstock. It is difficult to discuss, in absolute terms, the nature of space constricted reactions given the limitations of the equipment we have to study CFP. The theories and observations discussed here must be validated with future work, and fundamental studies with model compounds.

\section{Conclusions}

A large series of mesoporous MFI-type zeolite catalysts were prepared using a variety of topdown and bottom-up techniques. The acidity, textural properties, and pore size distribution of all materials were characterized and each material was evaluated with respect to the catalytic pyrolysis of cellulose and miscanthus.

This study suggests that mesoporous MFI catalysts are effective at increasing bio-oil yields from biomass CFP without sacrificing yields to valuable BTX compounds. The mesoporous ZSM-5 tailored using the mild desilication method produced the best results for CFP of both cellulose and miscanthus under the conditions studied. The increased yield to aromatics was accompanied with a significant decrease in the solid yield. It was theorized that catalyst improvements are primarily a result of enhanced accessibility to catalyst acid sites, resulting in cracking of bulky primary oxygenates, allowing them to enter the micropores for further 
reaction, leading to decreased rates of solid formation. Further increases in mesopore volume result in the negative consequence of a reduction in shape selectivity, and increased yields of larger compounds such as PAHs and coke. The ideal CFP catalyst requires both optimum acidity and pore size distribution. This study provides a unique comparison between materials prepared with a wide range of techniques and highlights how varying the zeolite mesoporosity affects biomass CFP product distributions.

\section{Acknowledgements}

This work was funded by NSF Award CBET-1236738. Funding for the research was also provided by the NSF GK-12 Program (Award Number 0947869). The authors would also like to acknowledge Rick Knurr (Dept. of Earth Sciences, University of Minnesota) for his help with ICP-OES analysis, and Matt Janish (Dept. of Materials Science \& Engineering, UConn) for help with TEM. 


\section{References}

[1] P. Thornley, K. Chong, T. Bridgwater, Environ. Sci. Policy 37 (2014) 255-265.

[2] A.V. Bridgwater, Biomass and Bioenergy 38 (2012) 68-94.

[3] C. Liu, H. Wang, A.M. Karim, J. Sun, Y. Wang, Chem. Soc. Rev. 43 (2014) ASAP.

[4] J. Jae, G.A. Tompsett, A.J. Foster, K.D. Hammond, S.M. Auerbach, R.F. Lobo, G.W. Huber, J. Catal. 279 (2011) 257-268.

[5] S. Du, Y. Sun, D.P. Gamliel, J.A. Valla, G.M. Bollas, Bioresour. Technol. 169 (2014) 188-97.

[6] V. Srinivasan, S. Adhikari, S.A. Chattanathan, S. Park, Energy \& Fuels (2012) 7347-7353.

[7] K. Wang, K.H. Kim, R.C. Brown, Green Chem. 16 (2014) 727.

[8] T.R. Carlson, Y. Cheng, J. Jae, G.W. Huber, Energy Environ. Sci. 4 (2011) 145-161.

[9] Y. Yu, X. Li, L. Su, Y. Zhang, Y. Wang, H. Zhang, Appl. Catal. A Gen. 447-448 (2012) 115123.

[10] J. Li, X. Li, G. Zhou, W. Wang, C. Wang, S. Komarneni, Y. Wang, Appl. Catal. A Gen. 470 (2014) 115-122.

[11] J.C. Groen, J. a. Moulijn, J. Perez-Ramirez, J. Mater. Chem. 16 (2006) 2121.

[12] F.C. Meunier, D. Verboekend, J. Pérez-Ramírez, J.-P. Gilson, J.C. Groen, Microporous Mesoporous Mater. 148 (2012) 115-121.

[13] B. Gil, Ł. Mokrzycki, B. Sulikowski, Z. Olejniczak, S. Walas, Catal. Today 152 (2010) 2432.

[14] D. Verboekend, J. Pérez-Ramírez, Catal. Sci. Technol. 1 (2011) 879.

[15] S.M. Campbell, J. Catal. 161 (1996) 338-349.

[16] C.S. Triantafillidis, A.G. Vlessidis, L. Nalbandian, N.P. Evmiridis, Microporous Mesoporous Mater. 47 (2001) 369-388.

[17] W.C. Yoo, X. Zhang, M. Tsapatsis, A. Stein, Microporous Mesoporous Mater. 149 (2012) 147-157.

[18] K. Li, J. Valla, J. Garcia-martinez, ChemCatChem 6 (2014) 46-66.

[19] J.C. Groen, L.A.A. Peffer, J.A. Moulijn, J. Pérez-Ramírez, Chem. - A Eur. J. 11 (2005) 498394.

[20] D. Verboekend, J. Pérez-Ramírez, Chem. - A Eur. J. 17 (2011) 1137-47.

[21] S. Abelló, A. Bonilla, J. Pérez-Ramírez, Appl. Catal. A Gen. 364 (2009) 191-198.

[22] Z. Wang, C. Li, H.J. Cho, S.-C. Kung, M.A. Snyder, W. Fan, J. Mater. Chem. A 3 (2015) 1298-1305. 
[23] H.I. Lee, H.J. Park, Y.K. Park, J.Y. Hur, J.K. Jeon, J.M. Kim, Catal. Today 132 (2008) 68-74.

[24] F.N. Gu, F. Wei, J.Y. Yang, N. Lin, W.G. Lin, Y. Wang, J.H. Zhu, Chem. Mater. 22 (2010) 2442-2450.

[25] A. Corma, V. Fornes, S.B. Pergher, T.L.M. Maesen, J.G. Buglass, Nature 396 (1998) 353356.

[26] W. Fan, M. a Snyder, S. Kumar, P.-S. Lee, W.C. Yoo, A. V McCormick, R. Lee Penn, A. Stein, M. Tsapatsis, Nat. Mater. 7 (2008) 984-991.

[27] H.J. Park, H.S. Heo, J.K. Jeon, J. Kim, R. Ryoo, K.E. Jeong, Y.K. Park, Appl. Catal. B Environ. 95 (2010) 365-373.

[28] M. Choi, H.S. Cho, R. Srivastava, C. Venkatesan, D.-H. Choi, R. Ryoo, Nat. Mater. 5 (2006) 718-723.

[29] H.J. Park, K.-H. Park, J.-K. Jeon, J. Kim, R. Ryoo, K.-E. Jeong, S.H. Park, Y.-K. Park, Fuel 97 (2012) 379-384.

[30] B. Puértolas, A. Veses, M.S. Callén, S. Mitchell, T. García, J. Pérez-Ramírez, ChemSusChem (2015) n/a-n/a.

[31] A.J. Foster, J. Jae, Y. Cheng, G.W. Huber, R.F. Lobo, Appl. Catal. A Gen. 423-424 (2012) 154-161.

[32] H. Mochizuki, T. Yokoi, H. Imai, R. Watanabe, S. Namba, J.N. Kondo, T. Tatsumi, Microporous Mesoporous Mater. 145 (2011) 165-171.

[33] P. Tarazona, Phys. Rev. A 31 (1985) 2672-2679.

[34] P. Tarazona, U. Marconi, R. Evans, Mol. Phys. 60 (1987) 573-595.

[35] M. Jaroniec, M. Kruk, J.P. Olivier, S. Koch., Stud. Surf. Sci. Catal. 128 (2000) 71-80.

[36] A.I. Biaglow, D.J. Parrillo, R.J. Gorte, J. Catal. 144 (1993) 193-201.

[37] O. Kresnawahjuesa, R.J. Gorte, C.A. Quierini, 210 (2002) 106-115.

[38] S. Du, J.A. Valla, G.M. Bollas, Green Chem. 15 (2013) 3214.

[39] D.P. Gamliel, S. Du, G.M. Bollas, J.A. Valla, Bioresour. Technol. 191 (2015) 187-196.

[40] K.S.W. Sing, D.H. Everett, R.A.W. Haul, L. Moscou, R.A. Pierotti, J. Rouquérol, T. Siemieniewska, Pure Appl. Chem. 57 (1985) 603-619.

[41] T. Armaroli, M. Trombetta, A. Gutièrrez Alejandre, J. Ramirez Solis, G. Busca, Phys. Chem. Chem. Phys. 2 (2000) 3341-3348.

[42] F. Schmidt, M.R. Lohe, B. Büchner, F. Giordanino, F. Bonino, S. Kaskel, Microporous Mesoporous Mater. 165 (2013) 148-157.

[43] C.A. Emeis, J. Catal. 141 (1993) 347-354. 
[44] P. Peng, Y. Wang, M.J. Rood, Z. Zhang, F. Subhan, Z. Yan, L. Qin, Z. Zhang, Z. Zhang, X. Gao, CrystEngComm 17 (2015) 3820-3828.

[45] M. Milina, S. Mitchell, N.L. Michels, J. Kenvin, J. Pérez-Ramírez, J. Catal. 308 (2013) 398407.

[46] F. Thibault-Starzyk, I. Stan, S. Abelló, A. Bonilla, K. Thomas, C. Fernandez, J.P. Gilson, J. Pérez-Ramírez, J. Catal. 264 (2009) 11-14.

[47] C. Fernandez, I. Stan, J.-P. Gilson, K. Thomas, A. Vicente, A. Bonilla, J. Pérez-Ramírez, Chem. - A Eur. J. 16 (2010) 6224-33.

[48] K. Mlekodaj, K. Sadowska, J. Datka, K. Góra-Marek, W. Makowski, Microporous Mesoporous Mater. 183 (2014) 54-61.

[49] P.R. Patwardhan, D.L. Dalluge, B.H. Shanks, R.C. Brown, Bioresour. Technol. 102 (2011) 5265-9.

[50] Y.-T. Cheng, G.W. Huber, ACS Catal. 1 (2011) 611-628.

[51] S. Du, D.P. Gamliel, M. V. Giotto, J.A. Valla, G.M. Bollas, Appl. Catal. A Gen. 513 (2016) 67-81.

[52] A.R. Teixeira, X. Qi, W.C. Conner, T.J. Mountziaris, W. Fan, P.J. Dauenhauer, Chem. Mater. (2015) 150612183612006.

[53] S. Wan, C. Waters, A. Stevens, A. Gumidyala, R. Jentoft, L. Lobban, D. Resasco, R. Mallinson, S. Crossley, ChemSusChem 8 (2015) 552-559. 


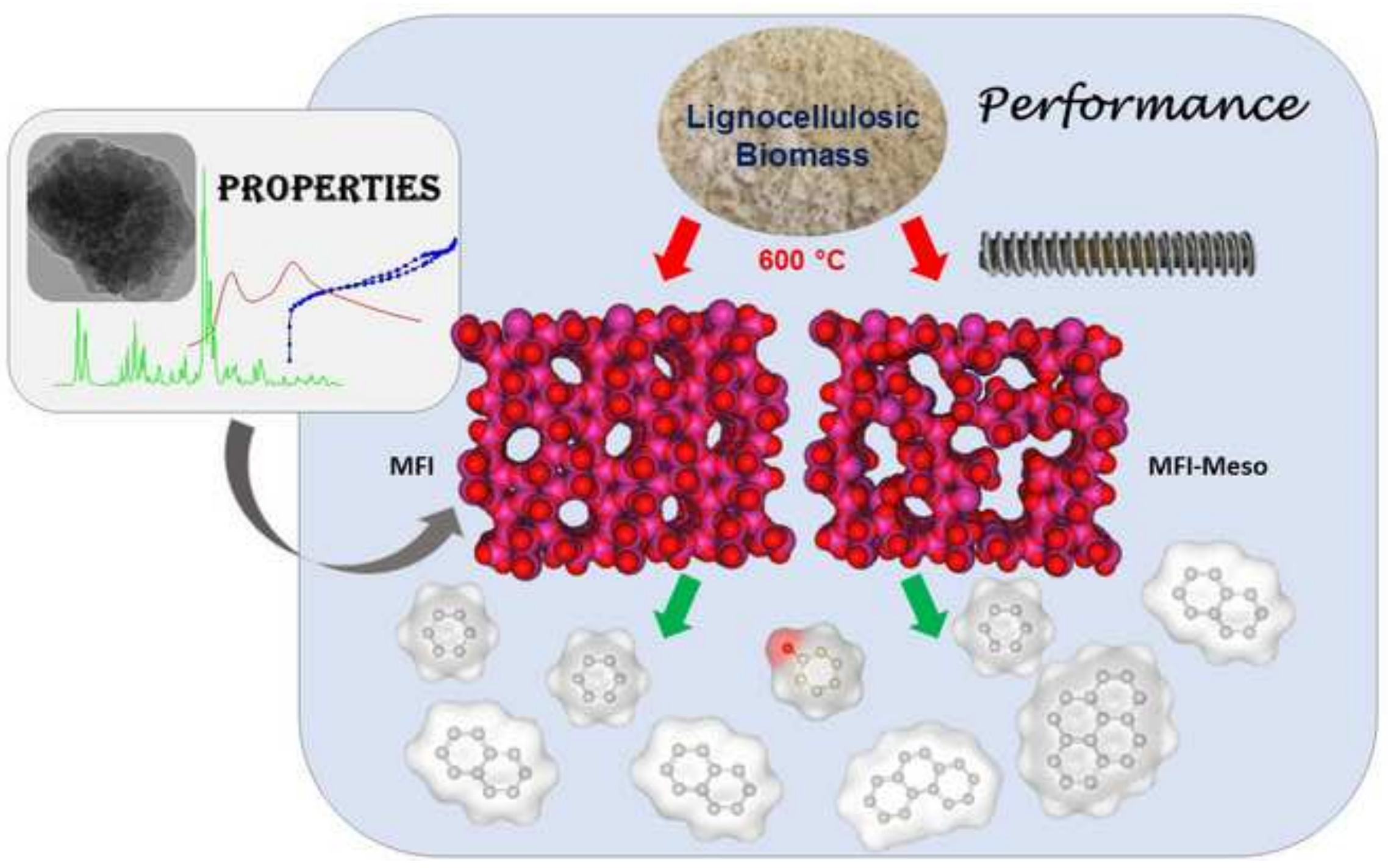

